\title{
On changes in the wind speed chart for the Brazilian territory used for structural design
}

\author{
Danilo L. Matias*, Débora M. Silva, Thiago D. dos Santos, Luiz C. M. Vieira Junior
}

\begin{abstract}
This paper aims to present an updated basic wind speed chart for the Brazilian territory, considering the data from airport weather stations recorded between 1950 and 2016. The design standard ABNT NBR 6123:1988 that defines the basic wind speed at a given location in Brazil is based on an outdated study, published more than 40 years ago, not comprising, then, the climate changes that occurred during this period. In addition, a trend analysis carried out for short, intermediate and long term is commented.
\end{abstract}

\section{Key words:}

Basic Wind Speed Chart, Trend Analysis, Structural Reliability

\section{Introduction}

Climate changing has affected society in a diversity of ways; from the structural engineer designer perspective, greater attention has been on changes on the wind speed and, thus, the reliability of structures designed using ABNT NBR 6123:1988 which defines the wind speed chart based on data recorded between 1950 and 1974 .

Santos et al. $(2016)^{1}$ reported that the probability of collapse of a given moment resistant steel frame can reach values twenty one times higher than is considered acceptable by the increment of wind loads. This reiterates the importance of studying the changes in wind regimes in the past forty years, under the perspective of structural reliability.

Therefore, this paper aims to present a contribution to the development of an updated basic wind speed chart for the Brazilian territory; we also present a simplified trend analysis focused on understanding future changes in the wind speed scenario in Brazil.

\section{Results and Discussion}

The basic wind speed chart presented in this study, Figure 1 , is the result of a large data compilation and analysis, comprising the records presented by Padaratz $(1977)^{2}$, previously used to develop the chart presented in ABNT NBR 6123:1988, and data from multiple Brazilian and neighbor countries airports stations, available on Wolfram Research Database (2017). The methodology used in this study was previously defined in Beck and Corrêa (2013) ${ }^{3}$.

When comparing the updated basic wind speed chart and the chart presented in ABNT NBR 6123:1988, one can conclude that for many locations the basic wind speed is higher than informed in the reference design standard; which also leads to the conclusion that structural engineers could be underestimating wind loading while designing a structure. At the same time, structures already built can be at risk, since the wind speed has increased along the years and, likely, the structural design was not rechecked for the newly imposed wind speed scenario.

A simplified trend analysis was carried out based on a linear regression of the maximum wind speed records for every station; the line defined in the regression was used to estimate the change in wind speed for the next 5, 20 and 100 years. Although this is a very simplified analysis, it clearly indicates that more studies shall be carried out to understand the fast changing wind speed scenario.

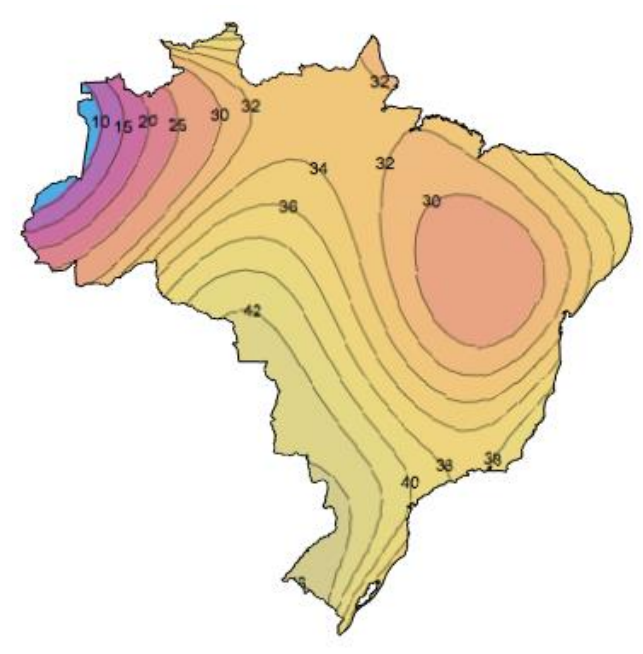

Figure 1. Updated basic wind speed chart in $\mathrm{m} / \mathrm{s}$

\section{Conclusions}

The design standard that provides the basic wind speed chart for the Brazilian territory has to be updated. In the Northeast and Central-West regions of Brazil, the speed chart does not provide adequate values for a 50 years return period. Instead, considering the wind speed data comprised between 1950 and 2016, the return period can be lower than 10 years.

Further research shall be carried out to predict the wind speed for a given time period, in order to establish adequate basic wind speeds and guarantee safety to structures and its users.

\section{Acknowledgement}

The authors acknowledge CNPq (National Council for Research and Development) and PIBIC/UNICAMP (Institutional Scientific Initiation Scholarship Program) by financially supporting this research.

\footnotetext{
${ }^{1}$ Santos, T.D.; Siqueira, G.H.; Vieira Junior, L.C.M. A stochastic approach for the wind load effect on steel structures. Revista Escola de Minas, Ouro Preto, n. 69 (2), p.137-145, 2016.

${ }^{2}$ Padaratz. I.J. Velocidade básica do vento no Brasil. Porto Alegre, RS, Brasil: UFRGS, 1977.

${ }^{3}$ Beck, A.T.; Corrêa, M.R.S. New design chart for basic wind speeds in Brazil. Latin American J. of Solids and Structures,v.10, p.707-723, 2013.
} 